\title{
Risk assessment of readmissions following an initial COPD-related hospitalization
}

This article was published in the following Dove Press journal: International Journal of COPD

II November 2013

Number of times this article has been viewed

\author{
Christine L Baker' \\ Kelly H Zou' \\ Jun $\mathrm{Su}^{2}$ \\ 'Pfizer Inc, New York, NY, \\ USA; ${ }^{2}$ Boehringer-Ingelheim \\ Pharmaceuticals Inc, Ridgefield, CT, \\ USA
}

Correspondence: Jun Su

Boehringer-Ingelheim Pharmaceuticals Inc, 900 Ridgebury Road, Ridgefield, CT 06877, USA

Tel + I 2037984788

Fax + I 2038374788

Email jun.su@boehringer-ingelheim.com
Background: Acute exacerbation of chronic obstructive pulmonary disease (COPD) is a leading cause of hospitalizations and readmissions in the US. Reducing the frequency of hospital readmission is a high priority of US health care organizations and government agencies. This study evaluated the risk factors associated with readmissions among commercially insured adults aged 40-65 years in the US who were hospitalized for COPD.

Methods: This retrospective cohort study used anonymized claims data from the Truven Health MarketScan ${ }^{\circledR}$ Commercial Claims and Encounters database. The patients included were aged 40-65 years, had an index hospitalization with a primary diagnosis of COPD between July 1 , 2008 and June 30, 2010 (continuously enrolled 12 months before and after), and were alive at hospital discharge. Patients with cystic fibrosis or tuberculosis or who were transferred to another inpatient facility after hospital discharge were excluded. All readmissions regardless of diagnosis, and separately a subset of all readmissions that had COPD as a primary or secondary diagnosis (COPD-related), were examined. Univariate descriptive statistics and multivariable regression methods were used.

Results: Of the 18,568 patients with index COPD hospitalizations, 6,095 (32.83\%) met the eligibility criteria. Of those, $503(8.25 \%)$ were readmitted within the first 30 days post-index hospitalization and 2,527 (41.46\%) within the first year (COPD-related 340 [5.58\%] and 1,681 [27.58\%], respectively). The median time to the first readmission post initial discharge was 4.0 months, with a mean of $5.0 \pm 3.4$ months. Multivariable regression analyses showed that comorbid conditions and health care utilization in the pre-index period were significant predictors for readmission both 30 and 90 days following index hospitalization.

Conclusion: A relatively high readmission rate was observed for patients aged 40-65 years. The results suggest that attention to patient comorbidities and pre-index/index health care service utilization may help identify hospitalized COPD patients at higher risk for readmission.

Keywords: chronic obstructive pulmonary disease, hospitalization, rehospitalization, readmission, noninterventional study, claims data, real-world data

\section{Introduction}

Chronic obstructive pulmonary disease (COPD) is a progressive disease that can negatively impact quality of life and is associated with an increased risk of morbidity and mortality. ${ }^{1,2}$ The decline in lung function of COPD patients tends to be associated with intermittent acute exacerbations (worsening of the condition). ${ }^{3,4}$

Acute exacerbation of COPD is a leading cause of hospitalizations and readmissions in the US. ${ }^{5-7}$ Reducing the frequency of hospital readmission is a high priority of health care organizations and government agencies, including the US Centers for 
Medicare and Medicaid Services (CMS). ${ }^{8}$ The goal of the CMS's National Strategy for Quality Improvement in Health Care is to reduce hospital readmission rates by $20 \%$ by the end of 2013. ${ }^{9}$ The CMS has identified early readmissions of patients with COPD as a future measure for hospital performance. ${ }^{10}$ In addition, the US Patient Protection and Affordable Care Act has sanctioned the development of the Hospital Readmission Reduction Program, which proposes to reduce all-cause hospital readmissions by aligning payment with outcome. ${ }^{11}$ As such, this program has established a reimbursement penalty for excess readmissions following index hospitalizations for acute myocardial infarction, heart failure, or pneumonia. COPD is another discharge diagnosis that is under consideration for eventual expansion of the program. ${ }^{8,11}$

This research aimed to identify factors associated with hospital readmission for COPD in order to potentially optimize COPD treatment and follow-up strategies. Studies based on real-world data that focus on risk factors contributing to readmission of COPD patients, particularly workingage patients diagnosed with this condition, are limited. Therefore, this retrospective, observational database study was conducted to describe the patient characteristics and examine risk factors associated with hospital readmission among adults in employer-sponsored health plans within the US who were hospitalized for COPD and were readmitted for any reason.

\section{Materials and methods Data source}

This retrospective study used anonymized real-world claims data from the Truven Health MarketScan ${ }^{\circledR}$ Commercial Claims and Encounters database. ${ }^{12}$ This database provides access to deidentified medical and prescription drug claims for individuals having an employer-sponsored health insurance plan in the US ${ }^{12}$ and has been used previously for COPD research. ${ }^{13}$ This study did not involve the collection, use, or transmittal of individually identifiable data, so was exempt from institutional review board approval.

\section{Inclusion and exclusion criteria}

Included in this analysis were patients aged 40-65 years who had an index hospitalization, defined as the first hospitalization with COPD as the primary diagnosis that occurred during the index period. The index period lasted for 2 years, from July 1, 2008 to June 30, 2010. The COPD diagnosis was determined using the International Classification of Diseases, the Ninth Revision, Clinical Modification (ICD-9-CM) codes 491.x (chronic bronchitis), 492.x (emphysema), and 496 (COPD, unspecified). ${ }^{14}$ Data were analyzed for 12 months before (pre-index) and 12 months after (post-index) the index hospitalization; therefore, patients must have been continuously enrolled during this time. ${ }^{15}$ Only patients who were alive at the time of index hospitalization discharge were included. Patients diagnosed with cystic fibrosis (ICD-9-CM 277.0x) or tuberculosis (ICD-9-CM 010.xx-018.xx) at any time during the study period on a nondiagnostic claim or who were transferred to another inpatient facility after hospital discharge were excluded. After applying the inclusion and exclusion criteria, 6,095 patients were eligible for analysis (Figure 1).

\section{Outcome measures}

The main objective of this study was to evaluate patient characteristics and clinical risk factors associated with the first hospital readmission that occurred within one year of the index hospitalization. A hospitalization was counted as a readmission if it occurred on any day following the date

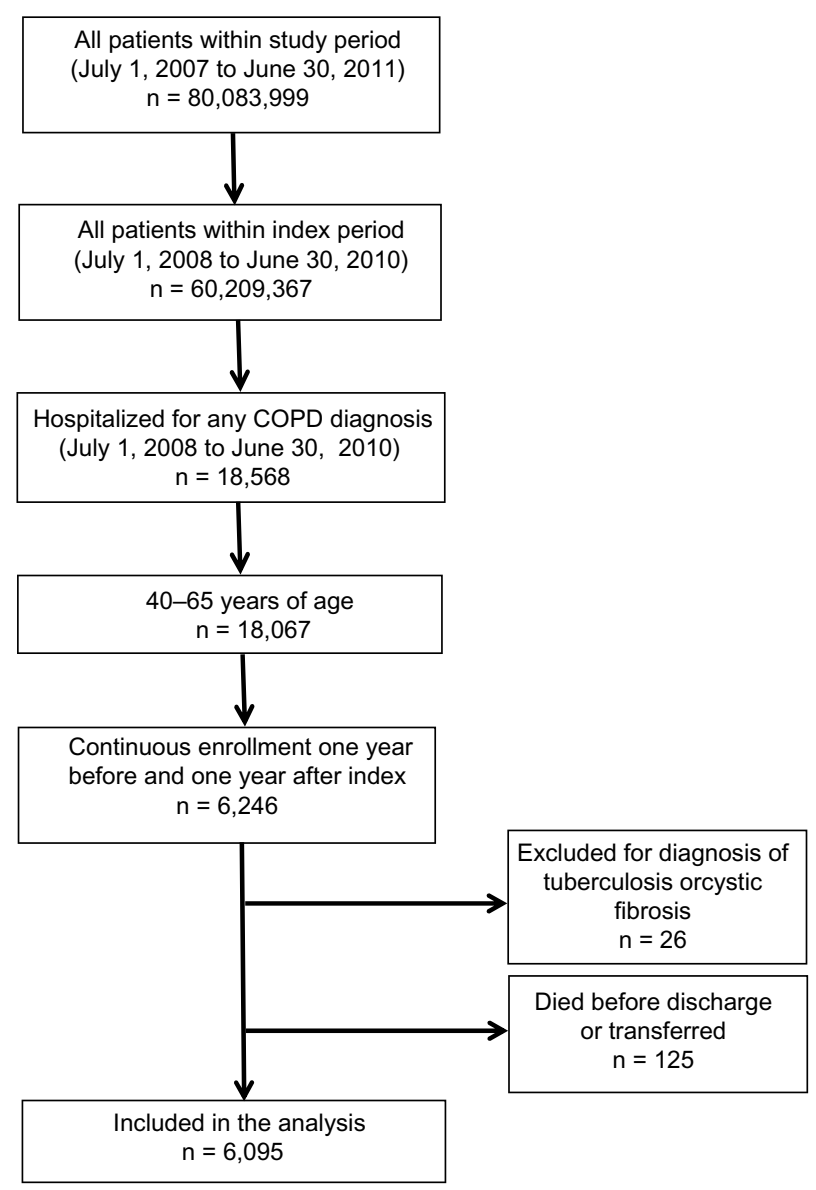

Figure I Patient flow diagram. Abbreviation: COPD, chronic obstructive pulmonary disease. 
of index hospitalization discharge; hospitalizations that occurred on the same day as index discharge were not counted as a readmission. Two definitions of readmission were used in the analyses: all readmissions that occurred during the post-index period regardless of diagnosis (all readmissions), and a subset of all readmissions that included only COPDrelated readmissions with a primary or secondary diagnosis of COPD during the readmission (COPD readmissions). An additional subset, defined using only a primary diagnosis of COPD on readmission, was examined. The results obtained were similar to the larger COPD subset defined above, so are not reported. Stratified analyses were performed using the amount of time (30 days, 90 days, or one year) between the index hospitalization and first hospital readmission.

\section{Baseline covariates}

The baseline covariates for hospital readmission in this analysis included age, gender, US geographic region, urban or rural area, insurance plan type, month and year of index hospitalization, respiratory medications within 90 days before index hospitalization, as well as COPD-related inpatient hospitalizations, COPD-related emergency department visits, and COPD-related outpatient visits during the preindex period. Additionally, the individual components of the Deyo-Charlson comorbidity index (CCI) were used to measure the pre-index comorbid conditions occurring in the patient population (see Supplementary Table). ${ }^{16}$

\section{Statistical analysis}

Descriptive statistics for categorical variables included percentages and for continuous variables included the mean, standard deviation, and median. The univariate Chi-square test was used on categorical variables for the two readmission types versus not readmitted. Multivariable stepwise logistic regression analysis was conducted to evaluate factors associated with readmission at 30 and 90 days post-index hospitalization. The baseline covariates used in this analysis are listed above. Odds ratios with $95 \%$ confidence intervals and $P$-values for the logistic regression analysis are reported. Statistical significance was reached when two-sided $P$-values were $\leq 0.05$. All univariate and multivariable analyses were performed using $\mathrm{SAS}^{\odot}$ version 9.2 software (SAS Institute, Cary, NC, USA).

\section{Results}

Of the 6,095 patients included in the analysis (Figure 1), $503(8.25 \%)$ were readmitted during the first 30 days postindex hospitalization (340 of the 503 readmitted patients, or $67.59 \%$, were readmitted for COPD, Figure 2). The percentages of patients with at least one hospital readmission increased over time, reaching 2,527 (41.46\%) readmitted patients at one year post-index (1,681 of the 2,527 readmitted patients, or $66.52 \%$, were readmitted for COPD). Nearly half of the readmitted patients were readmitted two or more times within one year post-index hospitalization (46.74\% all,

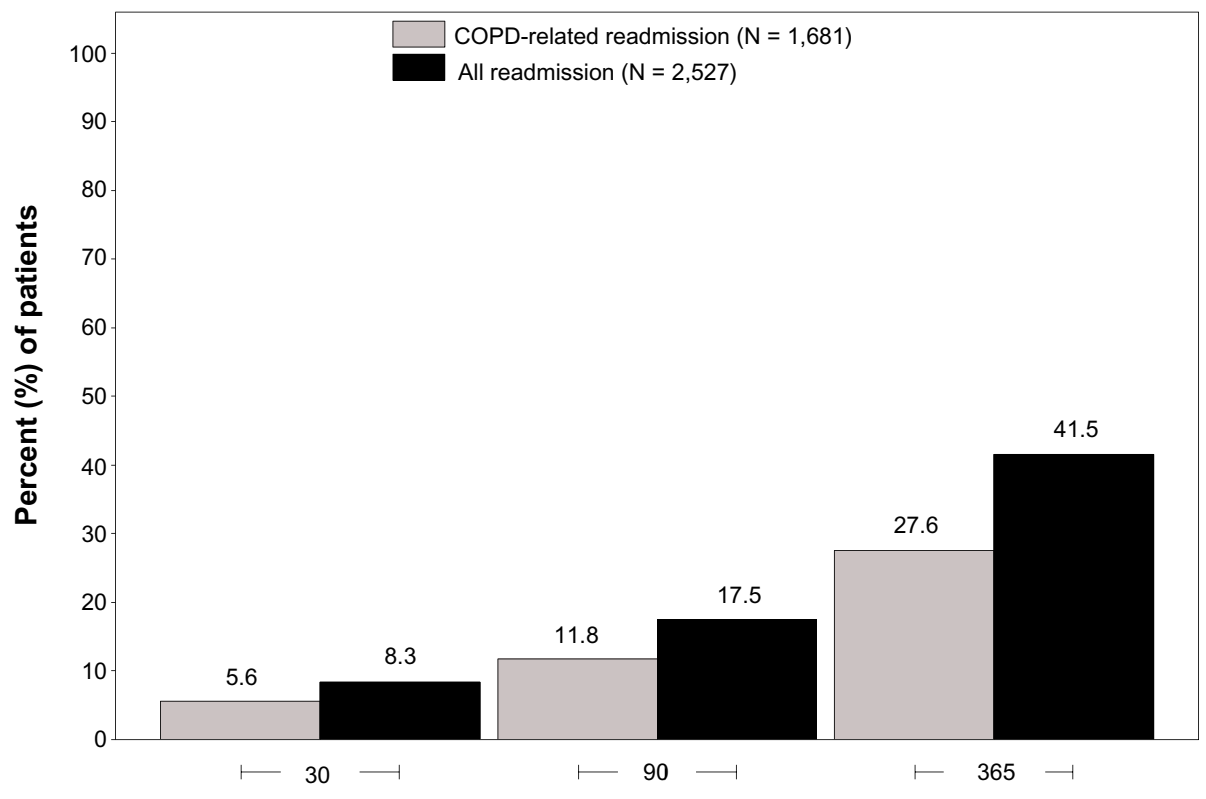

Time interval (days) since index hospitalization

Figure 2 Percentage of study sample readmitted by time to first readmission since the index hospitalization and readmission type $(n=6,095)$. Abbreviation: COPD, chronic obstructive pulmonary disease. 
$45.75 \%$ COPD-related). The means of the annual numbers of hospital readmissions were $2.08 \pm 1.78$ for all patients who had at least one readmission and $2.09 \pm 1.82$ for patients whose first readmission was COPD-related. The median time to first hospital readmission was 4.0 months, with a mean of $5.0 \pm 3.4$ months, for all readmitted patients. Similarly, a median of 4.0 months, with a mean of $4.94 \pm 3.40$ months, was observed for the patients readmitted for COPD. Time to first hospital readmission (months) since the index hospitalization for all readmitted patients is shown in a histogram in Figure 3.

Baseline demographic characteristics were similar between the groups (Table 1). The only significant difference was age as a categorical variable for the COPD-related readmitted patients versus those who were not readmitted $(P=0.0301)$. Readmitted patients were primarily women (59.20\%), who had a mean age of $57.75 \pm 5.20$ years and resided mostly in urban areas (76.61\%) and in the South region of the US (44.76\%) within the Marketscan database. The most prevalent insurance plan type among the readmitted patients was preferred provider organization (57.18\%).

In the pre-index period, aside from chronic pulmonary disease (all, 86.43\% and COPD-related, 91.55\% versus not readmitted, $79.18 \% ; P<0.0001$ for both comparisons), diabetes was the most frequent pre-index comorbidity among readmitted patients, with a significantly larger percentage of readmitted patients (all, 30.71\%; COPD-related, 27.66\%) than those who were not readmitted $(21.92 \%)$ having diabetes ( $P<0.0001$ for both comparisons). Each of the pre-index respiratory medications, except inhaled corticosteroids and mast cell stabilizers, were used by a significantly larger percentage of readmitted patients than those who were not readmitted (Table 2). Short-acting bronchodilators were the most frequently used pre-index respiratory medication, which were used by almost half of the readmitted patients (all, 46.42\%; COPD-related, 49.79\%), a significant difference from the patients who were not readmitted (39.97\%; $P<0.0001$ for both comparisons). Other pre-index Deyo-CCI comorbidities and respiratory medications that were significantly different between the readmitted patients and those who were not readmitted are shown in Table 2 .

In general, readmitted patients had significantly $(P<0.0001)$ more pre-index emergency department and outpatient visits for COPD than those who were not readmitted (Table 3). Approximately twice as many readmitted patients as those who were not readmitted had at least one inpatient hospitalization for COPD in the pre-index period $(P<0.0001)$.

Significant predictors for readmissions within 30 days or 90 days of the index hospitalization were largely related to comorbidities and pre-index hospitalizations (Tables 4 and 5). In general, patients with two or more pre-index hospitalizations for COPD were two to three times more likely to be readmitted for COPD than patients without any pre-index COPD hospitalizations. Comorbid conditions associated with the highest

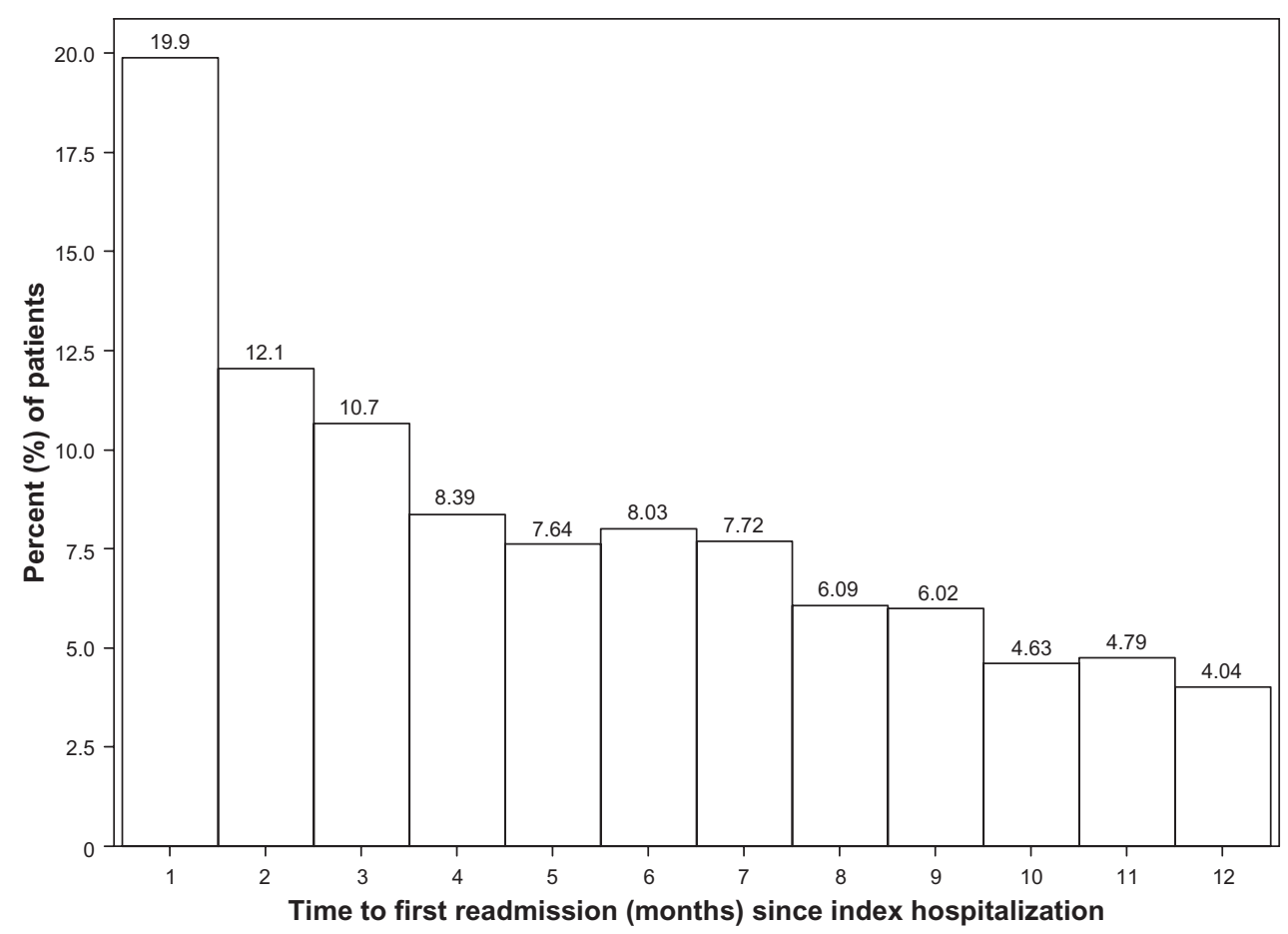

Figure 3 Time to first hospital readmission (months) since the index hospitalization for all readmitted patients $(n=2,527)$. 
Table I Baseline demographic characteristics (\% patients)

\begin{tabular}{|c|c|c|c|}
\hline Variable & $\begin{array}{l}\text { All } \\
\text { readmissions }{ }^{a} \\
(n=2,527)\end{array}$ & $\begin{array}{l}\text { COPD-related } \\
\text { readmissions } \\
(n=1,681)\end{array}$ & $\begin{array}{l}\text { Not } \\
\text { readmitted } \\
(n=3,568)\end{array}$ \\
\hline \multicolumn{4}{|l|}{ Gender } \\
\hline Male & 40.80 & 40.21 & 41.28 \\
\hline Female & 59.20 & 59.79 & 58.72 \\
\hline \multicolumn{4}{|c|}{ Age group, years* } \\
\hline $40-44$ & 1.98 & 1.55 & 2.30 \\
\hline $45-49$ & 6.57 & 5.95 & 7.06 \\
\hline $50-54$ & 16.70 & 15.11 & 16.87 \\
\hline $55-59$ & 28.21 & 29.33 & 29.32 \\
\hline $60-65$ & 45.94 & 48.07 & 44.45 \\
\hline \multicolumn{4}{|l|}{ Residence } \\
\hline Urban & 76.61 & 77.10 & 75.25 \\
\hline Rural & 23.39 & 22.90 & 24.75 \\
\hline \multicolumn{4}{|c|}{ US geographic region } \\
\hline South & 44.76 & 43.43 & 47.06 \\
\hline North central & 36.09 & 36.29 & 33.21 \\
\hline West & 9.85 & 10.59 & 10.34 \\
\hline Northeast & 9.22 & 9.58 & 9.22 \\
\hline Unknownc & 0.08 & 0.12 & 0.17 \\
\hline \multicolumn{4}{|c|}{ Insurance plan type } \\
\hline PPO & 57.18 & 57.53 & 57.96 \\
\hline $\mathrm{HMO}$ & 14.13 & 15.53 & 13.65 \\
\hline Comprehensive & $11.9 \mid$ & 12.43 & 10.96 \\
\hline POS & 10.37 & 8.51 & 10.01 \\
\hline Other & 6.41 & 6.01 & 7.43 \\
\hline
\end{tabular}

Notes: ${ }^{2}$ Defined as all readmissions that occurred during the follow-up period regardless of diagnosis; bdefined as a subset of all readmissions, which includes only readmissions where COPD was listed as a primary or secondary diagnosis; 'treated as missing in logistic regression. ${ }^{*} P=0.030$ I COPD-related readmissions versus not readmitted.

Abbreviations: COPD, chronic obstructive pulmonary disease; PPO, preferred provider organization; HMO, health maintenance organization; POS, noncapitated point-of-service.

risk of readmission within 30 days or 90 days of the index hospitalization included moderate or severe liver disease and metastatic solid tumor. Insurance plan (health maintenance organization versus comprehensive), and respiratory medications (long-acting bronchodilator, systemic corticosteroids) were not significant risk factors for readmission within 30 days of the index hospitalization but were within 90 days.

\section{Discussion}

The results of this study have identified the following predictors associated with a heightened rate of hospital readmission: pre-index comorbidities, respiratory medication use, and health care utilization. Specifically, it was found that 30-day and one-year hospital readmission rates were approximately $8 \%$ and $41 \%$, respectively, among patients with COPD aged 40-65 years who had employer-sponsored health insurance. Of the patients who were readmitted during the first 30 days post-index hospitalization, approximately two thirds (68\%) were readmitted for COPD. Thus, given
Table 2 Pre-index Deyo- $\mathrm{CCl}$ and respiratory medications (\% patients)

\begin{tabular}{|c|c|c|c|}
\hline Variable & $\begin{array}{l}\text { All } \\
\text { readmissions }^{a} \\
(n=2,527)\end{array}$ & $\begin{array}{l}\text { COPD-related } \\
\text { readmissions } \\
(\mathrm{n}=1,68 \mathrm{I})\end{array}$ & $\begin{array}{l}\text { Not } \\
\text { readmitted } \\
(n=3,568)\end{array}$ \\
\hline \multicolumn{4}{|c|}{ Deyo-CCl comorbidities } \\
\hline $\begin{array}{l}\text { Chronic } \\
\text { pulmonary disease }\end{array}$ & $86.43^{* *}$ & $91.55^{* *}$ & 79.18 \\
\hline Diabetes & $30.7 I^{* *}$ & 27.66 ** & 21.92 \\
\hline $\begin{array}{l}\text { Congestive } \\
\text { heart failure }\end{array}$ & $23.23 * *$ & $20.70^{* *}$ & $1 \mathrm{I} .46$ \\
\hline $\begin{array}{l}\text { Cerebrovascular } \\
\text { disease }\end{array}$ & $11.40 * *$ & $10.23 * *$ & 7.09 \\
\hline Malignancy & $11.12^{* *}$ & $10.59 * *$ & 6.75 \\
\hline $\begin{array}{l}\text { Peripheral } \\
\text { vascular disease }\end{array}$ & $7.84 * *$ & $6.96 *$ & 5.16 \\
\hline Renal disease & $7.64 * *$ & $6.25 * *$ & 3.34 \\
\hline $\begin{array}{l}\text { Myocardial } \\
\text { infarction }\end{array}$ & $7.32^{* *}$ & $7.50 * *$ & 3.81 \\
\hline $\begin{array}{l}\text { Diabetes } \\
\text { with chronic } \\
\text { complications }\end{array}$ & $6.61 * *$ & $5.77 * *$ & 3.31 \\
\hline $\begin{array}{l}\text { Rheumatologic } \\
\text { disease }\end{array}$ & $4.59 *$ & 3.57 & 3.11 \\
\hline $\begin{array}{l}\text { Metastatic solid } \\
\text { tumor }\end{array}$ & $2.14^{*}$ & $\mathrm{I} .84 *$ & 0.98 \\
\hline $\begin{array}{l}\text { Peptic ulcer } \\
\text { disease }\end{array}$ & 1.94 & 1.73 & 1.46 \\
\hline Mild liver disease & $1.62 *$ & I.49* & 0.70 \\
\hline $\begin{array}{l}\text { Moderate or severe } \\
\text { liver disease }\end{array}$ & $0.87^{*}$ & $0.7 I^{*}$ & 0.25 \\
\hline $\begin{array}{l}\text { Hemiplegia } \\
\text { or paraplegia }\end{array}$ & 0.67 & 0.48 & 0.34 \\
\hline AIDS & 0.24 & 0.24 & 0.08 \\
\hline Dementia & 0.12 & 0.00 & 0.08 \\
\hline Respiratory medic & cations ${ }^{c}$ & & \\
\hline $\begin{array}{l}\text { Short-acting } \\
\text { bronchodilator }\end{array}$ & $46.42^{* *}$ & $49.79 * *$ & 39.97 \\
\hline $\begin{array}{l}\text { Systemic } \\
\text { corticosteroid }\end{array}$ & $39.14 * *$ & $40.81 * *$ & 31.33 \\
\hline $\begin{array}{l}\text { Long-acting } \\
\text { bronchodilator }\end{array}$ & $35.22 * *$ & $40.04 * *$ & 27.72 \\
\hline Oxygen therapy & $32.49 * *$ & $35.5 I^{* *}$ & 19.14 \\
\hline $\begin{array}{l}\text { Inhaled } \\
\text { corticosteroid }\end{array}$ & 11.00 & 10.71 & 10.06 \\
\hline $\begin{array}{l}\text { Leukotriene } \\
\text { modifier }\end{array}$ & $9.8 I^{*}$ & $10.05^{*}$ & 7.34 \\
\hline Mast cell stabilizer & 0.04 & 0.06 & 0.03 \\
\hline
\end{tabular}

Notes: ${ }^{2}$ Defined as all readmissions that occurred during the follow-up period, regardless of diagnosis; 'defined as a subset of all readmissions, which includes only readmissions where COPD was listed as a primary or secondary diagnosis; 'within 90 -day period before index hospitalization. $* P<0.05$ versus not readmitted; $* * P<0.000$ I versus not readmitted.

Abbreviations: AIDS, acquired autoimmune deficiency syndrome; $\mathrm{CCl}$, Charlson comorbidity index; COPD, chronic obstructive pulmonary disease.

that one third of readmissions were not primarily related to COPD, paying greater attention to comorbid illness during a COPD exacerbation might prevent readmission, in addition to providing better overall long-term management of COPD. These data underscore the importance of 
Table 3 Pre-index health care utilization for COPD (\% patients)

\begin{tabular}{|c|c|c|c|}
\hline Variable & $\begin{array}{l}\text { All } \\
\text { readmissions }{ }^{a} \\
(n=2,527)\end{array}$ & $\begin{array}{l}\text { COPD-related } \\
\text { readmissions }^{\mathrm{b}} \\
(\mathrm{n}=\mathrm{I}, 68 \mathrm{I})\end{array}$ & $\begin{array}{l}\text { Not } \\
\text { readmitted } \\
(n=3,568) \\
\end{array}$ \\
\hline \multicolumn{4}{|c|}{ Inpatient hospitalizations $* *, c$} \\
\hline 0 & 73.05 & 68.41 & 89.41 \\
\hline I & 17.85 & 20.23 & 8.80 \\
\hline$\geq 2$ & 9.10 & 11.36 & 1.79 \\
\hline \multicolumn{4}{|c|}{ Emergency department visits $* *, c$} \\
\hline 0 & 28.49 & 25.76 & 32.48 \\
\hline I & 40.09 & 38.19 & 47.03 \\
\hline$\geq 2$ & 31.42 & 36.05 & 20.49 \\
\hline \multicolumn{4}{|c|}{ Outpatient visits**,c } \\
\hline 0 & 17.10 & 11.30 & 22.65 \\
\hline I & 9.62 & 7.56 & 12.22 \\
\hline$\geq 2$ & 73.29 & 81.14 & 65.13 \\
\hline
\end{tabular}

Notes: ${ }^{a}$ Defined as all readmissions that occurred during the follow-up period, regardless of diagnosis; bdefined as a subset of all readmissions, which includes only readmissions where COPD was listed as a primary or secondary diagnosis; 'required COPD diagnosis in any primary or secondary position. ${ }^{* * P}<0.0001$ versus not readmitted for both readmission types.

Abbreviations: COPD, chronic obstructive pulmonary disease.

identifying predictors for hospital readmission. Such results are relevant and timely, given the recent initiation of US government programs designed to reduce the frequency of hospital readmissions, especially within the first 30 days after the initial hospitalization. ${ }^{9-11}$ Therefore, attention to patient comorbidities and pre-index/index health care service utilization may help identify hospitalized COPD patients at heightened risk for readmission.

Other health care claims database studies have reported higher rates of 30-day readmissions than this study. Approximately $20 \%$ of fee-for-service Medicare beneficiaries hospitalized for COPD were readmitted within 30 days in the period of 2003-2004. ${ }^{5}$ In addition, a CMS-sponsored Medicare claims analysis of risk-standardized readmission rates following COPD hospitalization during the index year 2008 reported a 30 -day readmission rate of $21.8 \%$ among patients aged 65 years and older. ${ }^{10}$ Finally, according to a report based on the Healthcare Cost and Utilization Project of the Agency for Health Research and Quality, there were 190,700 index hospital admissions related to COPD across 15 states in 2008 among patients at least 40 years of age. ${ }^{17}$ The 30-day readmission rate related to COPD was between $7.1 \%$ and $17.3 \%$, depending on whether COPD was the principal diagnosis or not.

Several factors may contribute to these differences. First, other studies included Medicare and/or Medicaid beneficiaries and/or uninsured patients. These patient populations are generally older and have poorer health status than those in this study. Second, uninsured patients are more likely to
Table 4 Significant predictors of readmission within 30 days of index hospitalization

\begin{tabular}{|c|c|c|c|}
\hline Risk factor & OR & $95 \% \mathrm{Cl}$ & $\boldsymbol{P}$ \\
\hline \multicolumn{4}{|l|}{ All readmissions ${ }^{a}$} \\
\hline Moderate or severe liver disease & 3.09 & I.36-7.02 & 0.0070 \\
\hline Metastatic solid tumor & 2.44 & I.35-4.44 & 0.0034 \\
\hline $\begin{array}{l}\text { Number of IP hospitalizations } \\
\text { in pre-index period ( } \geq 2 \text { versus } 0)^{c}\end{array}$ & 2.25 & $1.6 \mathrm{I}-3.14$ & $<0.000$ I \\
\hline Congestive heart failure & 1.41 & $1.11-1.78$ & 0.0045 \\
\hline Diabetes & 1.35 & $1.10-1.66$ & 0.0046 \\
\hline $\begin{array}{l}\text { Number of ICU days in index } \\
\text { hospitalization }\end{array}$ & 1.04 & $1.00-1.09$ & 0.0479 \\
\hline $\begin{array}{l}\text { Year of index hospitalization } \\
\text { (2009 versus } 2008)\end{array}$ & 0.77 & $0.6 \mathrm{I}-0.97$ & 0.0238 \\
\hline \multicolumn{4}{|l|}{ COPD-related readmissions ${ }^{b}$} \\
\hline $\begin{array}{l}\text { Number of IP hospitalizations } \\
\text { in pre-index }(\geq 2 \text { versus } 0)^{c}\end{array}$ & 3.20 & $2.24-4.58$ & $<0.000$ I \\
\hline Chronic pulmonary disease & 2.52 & $1.56-4.05$ & 0.0001 \\
\hline Metastatic solid tumor & 2.26 & $\mid .21-4.25$ & 0.0109 \\
\hline $\begin{array}{l}\text { Number of IP hospitalizations } \\
\text { in pre-index (I versus } 0)^{c}\end{array}$ & 1.39 & $1.02-1.90$ & 0.0357 \\
\hline $\begin{array}{l}\text { Number of ICU days in index } \\
\text { hospitalization }\end{array}$ & 1.05 & $1.00-1.10$ & 0.0356 \\
\hline $\begin{array}{l}\text { Year of index hospitalization } \\
\text { (2009 versus } 2008)\end{array}$ & 0.76 & $0.58-0.99$ & 0.0455 \\
\hline
\end{tabular}

Notes: apefined as all readmissions that occurred during the follow-up period, regardless of diagnosis; b befined as a subset of all readmissions, which includes only readmissions where COPD was listed as a primary or secondary diagnosis; 'required COPD diagnosis in any primary or secondary position. Statistically significant odds ratios are reported when the corresponding two-sided $P$-values are $\leq 0.05$ from multivariable stepwise logistic regression analyses.

Abbreviations: IP, inpatient; ICU, intensive care unit; $\mathrm{Cl}$, confidence interval; OR, odds ratio.

seek care from the emergency department than those who are insured, which could lead to a higher rate of emergency department visits leading to readmission. Third, the quality of care and treatment received during and immediately after hospitalization is potentially a factor. Studies suggest that early follow-up care after hospital discharge, continuity of care with a primary care physician or pulmonologist, and other supportive measures might reduce early readmission rates for COPD. ${ }^{18-20}$ Finally, individuals with employer-sponsored health insurance might be more likely to engage in preventative health care measures than uninsured individuals.

The association of comorbidities with readmission is not surprising given that COPD often coexists with other diseases. ${ }^{21-23}$ Other studies have reported high rates of mortality and adverse outcomes, including readmission, among COPD patients who have comorbid medical conditions..$^{24,25}$ Consistent with other studies, ${ }^{20,22,26-28}$ congestive heart failure was associated with a higher rate of all readmissions within 30 or 90 days of the index hospitalization in the present study. Here, approximately one quarter of this age group had congestive heart failure during the year before the 
Table 5 Significant predictors for readmissions within 90 days of index hospitalization

\begin{tabular}{|c|c|c|c|}
\hline Risk factor & OR & $95 \% \mathrm{Cl}$ & $P$ \\
\hline \multicolumn{4}{|l|}{ All readmissions ${ }^{a}$} \\
\hline Moderate or severe liver disease & 3.10 & I.47-6.54 & 0.0029 \\
\hline $\begin{array}{l}\text { Number of IP hospitalizations } \\
\text { in pre-index ( } \geq 2 \text { versus } 0)^{c}\end{array}$ & 2.90 & $2.21-3.80$ & $<0.0001$ \\
\hline Metastatic solid tumor & 1.69 & $\mathrm{I} .0 \mathrm{I}-2.8 \mathrm{I}$ & 0.0447 \\
\hline Congestive heart failure & 1.50 & $1.25-1.79$ & $<0.0001$ \\
\hline Plan type (HMO versus comprehensive) & 1.46 & $1.11-1.92$ & 0.0072 \\
\hline Renal disease & 1.43 & $1.09-1.89$ & 0.0102 \\
\hline $\begin{array}{l}\text { Number of IP hospitalizations } \\
\text { in pre-index (I versus } 0)^{c}\end{array}$ & 1.39 & $1.14-1.69$ & 0.0013 \\
\hline Myocardial infarction & 1.31 & $1.00-1.72$ & 0.0481 \\
\hline Malignancy & 1.29 & $1.01-1.65$ & 0.0394 \\
\hline & \multicolumn{2}{|c|}{$(\geq 2 \text { versus } 0)^{c}$} & 0.0149 \\
\hline Systemic corticosteroids ${ }^{\mathrm{d}}$ & 1.22 & $|.06-| .4 \mid$ & 0.0072 \\
\hline Diabetes & 1.20 & $|.03-1.4|$ & 0.0199 \\
\hline $\begin{array}{l}\text { Number of ICU days in index } \\
\text { hospitalization }\end{array}$ & 1.04 & $1.00-1.07$ & 0.0413 \\
\hline \multicolumn{4}{|l|}{ COPD-related readmissions $\mathrm{s}^{\mathrm{b}}$} \\
\hline $\begin{array}{l}\text { Number of IP hospitalizations } \\
\text { in pre-index ( } \geq 2 \text { versus } 0)^{c}\end{array}$ & 3.92 & $2.95-5.20$ & $<0.0001$ \\
\hline Moderate or severe liver disease & 2.79 & $1.23-6.34$ & 0.0143 \\
\hline Metastatic solid tumor & 1.82 & $1.08-3.10$ & 0.0258 \\
\hline Plan type (HMO versus comprehensive) & 1.62 & $1.17-2.23$ & 0.0034 \\
\hline $\begin{array}{l}\text { Number of } O P \text { visits in pre-index } \\
(\geq 2 \text { versus } 0)^{c}\end{array}$ & 1.61 & $1.29-2.01$ & $<0.0001$ \\
\hline $\begin{array}{l}\text { Number of IP hospitalizations } \\
\text { in pre-index (I versus } 0)^{c}\end{array}$ & 1.61 & $1.14-2.26$ & 0.0064 \\
\hline Long-acting bronchodilator treatment ${ }^{d}$ & 1.21 & $1.02-1.45$ & 0.0313 \\
\hline $\begin{array}{l}\text { Number of ICU days in index } \\
\text { hospitalization }\end{array}$ & 1.04 & $1.00-1.08$ & 0.0348 \\
\hline
\end{tabular}

Notes: ${ }^{a}$ Defined as all readmissions that occurred during the follow-up period, regardless of diagnosis; bdefined as a subset of all readmissions, which includes only readmissions where COPD was listed as a primary or secondary diagnosis; 'required COPD diagnosis in any primary or secondary position; ${ }^{d}$ within 90 -day period before index hospitalization. Statistically significant odds ratios are reported when corresponding two-sided $P$-values are $\leq 0.05$ from multivariable stepwise logistic regression analyses.

Abbreviations: $\mathrm{Cl}$, confidence interval; COPD, chronic obstructive pulmonary disease; ED, emergency department; $\mathrm{HMO}$, health maintenance organization; ICU, intensive care unit; IP, inpatient; OP, outpatient; OR, odds ratio.

index hospitalization. In contrast, although close to one third of the patients had pre-index diabetes, this was not associated with a higher rate of COPD-related readmissions. This lack of association might be due, at least in part, to the regular interaction between patients with diabetes and their health care providers, resulting in early detection and treatment of COPD exacerbations. ${ }^{29}$ Finally, pre-index use of systemic corticosteroids and long-acting bronchodilators, but not inhaled corticosteroids or oxygen therapy, were found to be significant predictors for readmission within 90 days of the index hospitalization. A recent Spanish study reported other factors that were associated with a greater probability of readmission among patients with COPD, including increased systemic inflammation, increased respiratory failure, and reduced levels of physical activity. ${ }^{30}$ Prospective, long-term studies are needed.

The strengths of this study include the following: examination of an understudied population of younger patients with COPD; the time periods (within 30 days or 90 days of index hospitalization) investigated in the predictors for readmission analysis are relevant to the current CMS and Affordable Care Act guidelines for reducing hospital readmission rates; ${ }^{9}$ use of a large patient database containing real-world information; and use of well known diagnosis and comorbidity instruments (ICD-9-CM codes and Deyo-CCI) that may be useful in other COPD database studies. However, it should also be noted that there are several potential limitations of this study. Given that we analyzed a group of patients with employer-sponsored health insurance, our results might not be generalizable to the entire US population. ${ }^{13}$ In addition, the results must be considered in light of the inherent limitations of a retrospective claims analysis, such as lack of mortality data, inability to determine definitively the occurrence of an exacerbation of COPD or measure severity and duration of disease; lack of randomization; potential for inaccurate or missing diagnosis coding; and lack of information on race, socioeconomic status, smoking history, and other potential confounding variables, such as planned readmissions.

\section{Conclusion}

Among commercially insured patients aged 40-65 years, the rate of readmission after an index hospitalization for COPD was $8.25 \%$ within 30 days after an index hospitalization for COPD. Significant predictors for readmission were largely related to comorbidities and pre-index/index health care utilization. Attention to such predictors may help identify hospitalized COPD patients at heightened risk for readmission.

\section{Author contributions}

All authors met the criteria for authorship as recommended by the International Committee of Medical Journal Editors and were fully responsible for all content and editorial decisions, and were involved at all stages of manuscript development.

\section{Acknowledgments and disclosure}

This research was supported by Pfizer Inc and BoehringerIngelheim Pharmaceuticals Inc. The authors would like to acknowledge Yanni Yu of Boehringer-Ingelheim Inc for her contributions to the initial design of the study. Editorial/ medical writing support was provided by Cindy C Taylor 
and was funded by Pfizer Inc and Boehringer-Ingelheim Pharmaceuticals Inc. Statistical programming oversight was conducted by the Clinical Informatics and Innovation, Information Strategy and Analytics, Pfizer Inc. CLB and KHZ are employees of Pfizer Inc, which cosponsored this analysis. JS is an employee of Boehringer-Ingelheim Pharmaceuticals Inc, which cosponsored this analysis.

\section{References}

1. Shavelle RM, Paculdo DR, Kush SJ, Mannino DM, Strauss DJ. Life expectancy and years of life lost in chronic obstructive pulmonary disease: findings from the NHANES III follow-up study. Int J Chron Obstruct Pulmon Dis. 2009;4:137-148.

2. Mannino DM, Homa DM, Akinbami LJ, Ford ES, Redd SC. Chronic obstructive pulmonary disease surveillance - United States, 1971-2000. Respir Care. 2002;47:1184-1199.

3. Spencer S, Calverley PM, Burge PS, Jones PW. Impact of preventing exacerbations on deterioration of health status in COPD. Eur Respir J. 2004;23:698-702.

4. Makris D, Moschandreas J, Damianaki A, et al. Exacerbations and lung function decline in COPD: new insights in current and ex-smokers. Respir Med. 2007;101:1305-1312.

5. Jencks SF, Williams MV, Coleman EA. Rehospitalizations among patients in the Medicare fee-for-service program. $N$ Engl J Med. 2009;360:1418-1428.

6. HCUPnet. Agency for Healthcare Research and Quality (1997-2008). Healthcare Cost and Utilization Project (HCUP) Nationwide Inpatient Sample (NIS). Available from: http://hcupnet.ahrq.gov/HCUPnet.jsp? $\mathrm{Id}=226284 \mathrm{BF} 0$ BAE1506\&Form $=$ SelLAY \&JS $=$ Y \&Action $=\% 3 \mathrm{E} \% 3 \mathrm{E}$ Next\%3E\%3E\&_LAY=Researcher. Accessed February 26, 2013.

7. Perera PN, Armstrong EP, Sherrill DL, Skrepnek GH. Acute exacerbations of COPD in the United States: inpatient burden and predictors of costs and mortality. COPD. 2012;9:131-141.

8. Kocher RP, Adashi EY. Hospital readmissions and the Affordable Care Act: paying for coordinated quality care. JAMA. 2011;306: 1794-1795.

9. HeatlhCare.gov. Report to Congress: national strategy for quality improvement in health care. Available from: http://www.healthcare.gov/ center/reports/quality03212011a.html. Accessed February 14, 2013.

10. National Quality Forum. Measure 1891: Hospital 30-day, all-cause, risk-standardized readmission rate (RSRR) following chronic obstructive pulmonary disease (COPD) hospitalization. Available from: http://www.qualityforum.org/Projects/n-r/Pulmonary_Endorsement_ Maintenance/1891_30_Day_RSRR_COPD.aspx. Accessed June 13, 2013.

11. CMS.gov. Centers for Medicare and Medicaid Services. Proposed changes to the inpatient PPS for acute care and the long-term care PPS and FY 2012 rates. Available from: http://www.gpo.gov/fdsys/ pkg/FR-2011-2005-05/pdf/2011-9644.pdf. Accessed February 14, 2013.

12. Truven Health Analytics. Available from: http://www.truvenhealth. com. Accessed March 25, 2013.

13. Cao Z, Zou KH, Baker CL, et al. Respiratory-related medical expenditure and inpatient utilisation among COPD patients receiving long-acting bronchodilator therapy. J Med Econ. 2011;14:147-158.
14. Stein BD, Charbeneau JT, Lee TA, et al. Hospitalizations for acute exacerbations of chronic obstructive pulmonary disease: how you count matters. COPD. 2010;7:164-171.

15. Dalal AA, Shah M, D'Souza AO, Rane P. Costs of inpatient and emergency department care for chronic obstructive pulmonary disease in an elderly Medicare population. J Med Econ. 2010;13:591-598.

16. Deyo RA, Cherkin DC, Ciol MA. Adapting a clinical comorbidity index for use with ICD-9-CM administrative databases. J Clin Epidemiol. 1992;45:613-619.

17. Elixhauser AA, Hau DH, Podulka J. Readmission for chronic obstructive pulmonary disease, 2008. HCUP Statistical Brief \#121: Healthcare Cost and Utilization Project; 2008. Available from: http://www.hcup-us. ahrq.gov/reports/statbriefs/sb121.pdf. Accessed August 15, 2013.

18. Lawlor M, Kealy S, Agnew M, et al. Early discharge care with ongoing follow-up support may reduce hospital readmissions in COPD. Int $J$ Chron Obstruct Pulmon Dis. 2009;4:55-60.

19. Sharma G, Kuo YF, Freeman JL, Zhang DD, Goodwin JS. Outpatient follow-up visit and 30-day emergency department visit and readmission in patients hospitalized for chronic obstructive pulmonary disease. Arch Intern Med. 2010;170:1664-1670.

20. Nantsupawat T, Limsuwat C, Nugent K. Factors affecting chronic obstructive pulmonary disease early rehospitalization. Chron Respir Dis. 2012;9:93-98.

21. Minakata Y, Sugiura H, Yamagata T, et al. Prevalence of COPD in primary care clinics: correlation with non-respiratory diseases. Intern Med. 2008;47:77-82.

22. Holguin F, Folch E, Redd SC, Mannino DM. Comorbidity and mortality in COPD-related hospitalizations in the United States, 1979 to 2001. Chest. 2005;128:2005-2011.

23. Rana JS, Mittleman MA, Sheikh J, et al. Chronic obstructive pulmonary disease, asthma, and risk of type 2 diabetes in women. Diabetes Care. 2004;27:2478-2484.

24. Antonelli Incalzi R, Fuso L, De Rosa M, et al. Co-morbidity contributes to predict mortality of patients with chronic obstructive pulmonary disease. Eur Respir J. 1997;10:2794-2800.

25. Matkovic Z, Huerta A, Soler N, et al. Predictors of adverse outcome in patients hospitalised for exacerbation of chronic obstructive pulmonary disease. Respiration. 2012;84:17-26.

26. Chen Y, Li Q, Johansen H. Age and sex variations in hospital readmissions for COPD associated with overall and cardiac comorbidity. Int J Tuberc Lung Dis. 2009;13:394-399.

27. Dalal AA, Shah M, Lunacsek O, Hanania NA. Clinical and economic burden of patients diagnosed with COPD with comorbid cardiovascular disease. Respir Med. 2011;105:1516-1522.

28. Roberts CM, Stone RA, Lowe D, Pursey NA, Buckingham RJ. Comorbidities and 90-day outcomes in hospitalized COPD exacerbations. COPD. 2011;8:354-361.

29. McGhan R, Radcliff T, Fish R, et al. Predictors of rehospitalization and death after a severe exacerbation of COPD. Chest. 2007;132: $1748-1755$.

30. Garcia-Polo C, Alcazar-Navarrete B, Ruiz-Iturriaga LA, et al. Factors associated with high healthcare resource utilisation among COPD patients. Respir Med. 2012;106:1734-1742. 


\section{Supplementary table}

Table SI Comorbidity categories used in the Deyo-Charlson comorbidity index algorithm

\begin{tabular}{|c|c|}
\hline Conditions & ICD-9 codes \\
\hline Acquired autoimmune deficiency syndrome & $042-044.9$ \\
\hline Any malignancy, including lymphoma & |40-|72.9, I74-195.8, \\
\hline and leukemia & 200-208.9 \\
\hline Cerebrovascular disease & $430-438 . x x$ \\
\hline Chronic pulmonary disease & $490-496,500-505,506.4$ \\
\hline Congestive heart failure & $428-428.9$ \\
\hline \multirow[t]{2}{*}{ Connective tissue disease } & $710.0,710.1,710.4$ \\
\hline & $7|4.0-7| 4.2,7|4.8|, 725$ \\
\hline Dementia & $290-290.9$ \\
\hline Diabetes mellitus & $250-250.3,250.7$ \\
\hline Diabetes with end organ disease & $250.4-250.6$ \\
\hline Hemiplegia or paraplegia & $344.1,342-342.9$ \\
\hline Metastatic solid tumor & $196-199.1$ \\
\hline \multirow[t]{2}{*}{ Mild liver disease } & 57I.2, 57I.5, 57I.6, \\
\hline & $571.4-571.49$ \\
\hline Moderate or severe liver disease & $572.2-572.8,456.0-456.21$ \\
\hline \multirow[t]{2}{*}{ Moderate or severe renal disease } & 582-582.9, 583-583.7, \\
\hline & $585 . x x, 586,588-588.9$ \\
\hline Myocardial infarction & $412,410-410.9$ \\
\hline \multirow[t]{2}{*}{ Peripheral vascular disease } & $44 I-44 I .9,443.9,785.4$ \\
\hline & V43.4 \\
\hline Ulcer & $531-534.9$ \\
\hline
\end{tabular}

International Journal of COPD

\section{Publish your work in this journal}

The International Journal of COPD is an international, peer-reviewed journal of therapeutics and pharmacology focusing on concise rapid reporting of clinical studies and reviews in COPD. Special focus is given to the pathophysiological processes underlying the disease, intervention programs, patient focused education, and self management protocols.

\section{Dovepress}

This journal is indexed on PubMed Central, MedLine and CAS. The manuscript management system is completely online and includes a very quick and fair peer-review system, which is all easy to use. Visit http://www.dovepress.com/testimonials.php to read real quotes from published authors. 